Open Access

\title{
Medicinal herb extracts ameliorate impaired growth performance and intestinal lesion of newborn piglets challenged with the virulent porcine epidemic diarrhea virus
}

\author{
Hyeun Bum Kim ${ }^{1}$, Chul Young Lee ${ }^{2}$, Sung Jae Kim³ , Jeong Hee Han ${ }^{3^{*}}$ and Keum Hwa Choi ${ }^{4^{*}}$
}

\begin{abstract}
The objective of this study was to evaluate effects of a combined use of extracts of medicinal herbs Taraxaumi mongolicum, Viola yedoensis Makino, Rhizoma coptidis, and Radix isatidis (MYCl) on porcine epidemic diarrhea (PED). Twenty-two 3-day-old piglets received an oral challenge with $3 \times 10^{3.5} \mathrm{TCID}_{50}$ of the virulent PED virus (PEDV) in PBS or PBS only and daily oral administration of $60 \mathrm{mg}$ of the MYCI mixture suspended in milk replacer or the vehicle for 7 days in a $2 \times 2$ factorial arrangement of treatments. Average daily gain (ADG) increased $(p<0.05)$ in response to the MYCI treatment in the PEDV-challenged piglets ( $-18 \mathrm{vs} .7 \mathrm{~g}$ for the vehicle- vs. MYCl-administered group), but not in unchallenged animals (27 vs. $28 \mathrm{~g}$ ). Diarrhea score and fecal PEDV shedding, however, were not influenced by the MYCl treatment. The PEDV challenge caused severe intestinal villus atrophy and crypt hyperplasia, both of which were alleviated by administration of the MYCI mixture as indicated by an increase in the villus height and a decrease in the crypt depth due to the treatment. Overall, medicinal herb extracts used in this study ameliorated impaired growth performance and intestinal lesion of newborn piglets challenged with the virulent PEDV. Therefore, our results suggest that the MYCI mixture could be used as a prophylactic or therapeutic agent against PED.
\end{abstract}

Keywords: Health, Medicinal herb, Pigs, Porcine epidemic diarrhea

\section{Background}

The porcine epidemic diarrhea virus (PEDV) or genus Alphacoronavirus causes an acute or sub-acute gastrointestinal disorder in pigs of all ages resulting in serious economic losses across Europe and Asia [1-3]. Primary clinical symptoms of the PEDV infection include acute diarrhea, vomiting, weight loss, and dehydration $[4,5]$. Moreover, an increased mortality as well as higher morbidity in suckling piglets vs. older ones has also been reported as to the damage of PEDV infection [6]. Many attempts have been made to find effective prophylactic or

\footnotetext{
* Correspondence: hanjh@kangwon.ac.kr; choix006@umn.edu

${ }^{3}$ Department of Veterinary Pathology, College of Veterinary Medicine and Institute of Veterinary Science, Kangwon National University, Chuncheon 200-701, South Korea

${ }^{4}$ Department of Complementary and Alternative Medicine, College of Veterinary Medicine, University of Minnesota, Saint Paul 55108, USA Full list of author information is available at the end of the article
}

therapeutic agents against PEDV infection, but no satisfactory agent has been reported to date $[7,8]$.

Medicinal herbs have been used as antimicrobial agents for many years in Asian countries [9-12]. For example, extracts of Houttuynia cordata are known to be effective against herpes simplex virus type 1 (HSV-1), influenza virus, human immunodeficiency virus type 1 (HIV-1) [13], and coronavirus [14]. Moreover, Taraxacum mongolicum, Viola yedoensis Makino, Rhizoma coptidis, and Radix isatidis, which have been selected for the present study, are also known to have antimicrobial and antiviral properties [15]. Taraxacum mongolicum has anti-inflammatory, anti-carcinogenic, anti-allergic and anti-viral properties [16-18] whereas extracts of Viola yedoensis Makino have antiviral and antibacterial activities against HSV-1 and Bacillus subtilis [19, 20]. Rhizoma coptidis, which contains berberine as one of its active components, has a potent antiviral activity against herpes virus as well as an 
antibacterial activity [21, 22]. Radix isatidis, roots and leaves of which have been used in traditional Eastern medicine for centuries to treat upper respiratory infections and encephalitis, has been reported to have anti-inflammatory [23] and antiviral effects against hepatitis, severe acute respiratory syndrome (SARS), influenza, and epidemic encephalitis [24] as well as a stimulatory action on macrophage phagocytosis [25].

Taraxacum mongolicum, Radix isatidis, Viola yedoensis Makino, Rhizoma coptidis, and Radix isatidis are potentially useful medicinal herbs for PED as could be extrapolated from their antimicrobial activities described above. To our knowledge, however, such a possibility has not been examined to date. The present study was therefore conducted to investigate the effects of a combined mixture of extracts of the four herbs (MYCI) on growth performance, diarrhea, and intestinal morphology in newborn piglets challenged with PEDV.

\section{Methods}

\section{Animals and treatments}

The experimental protocol regarding animal management and care was approved by the Animal Care and Use Committee of Kangwon National University. The MYCI reagent used in the present study was prepared by mixing powdered extracts of Taraxaci mongolia, Viola yedoensis Makino, Rhizoma coptidis and Radix isatidis (Mayway Co., USA) at a ratio of 1:1:1:2. Twenty-two 3-day-old cross-bred $[($ Landrace $\times$ Yorkshire $) \times$ Duroc $]$ suckling piglets were obtained from a commercial farm that had not implemented PEDV vaccination. The piglets were housed individually and randomly assigned to one of four experimental groups in a $2 \times 2$ factorial arrangement of treatments with respect to a PEDV challenge and administration of the MYCI mixture. The animals received an oral administration of $3 \times 10^{3.5} \mathrm{TCID}_{50}$ of PEDV in $3 \mathrm{~mL}$ of phosphate-buffered saline (PBS) or PBS only following 12$\mathrm{h}$ fasting and daily administration of $60 \mathrm{mg}$ of the MYCI mixture suspended in $1 \mathrm{~mL}$ of milk replacer (CJ Feed, Inc., Seoul) or the vehicle for 7 days. Calculated chemical composition of the milk replacer is presented in Table 1. All animals had a free access to water and the milk replacer

Table 1 Calculated chemical composition of the milk replacer

\begin{tabular}{ll}
\hline Item & Value \\
\hline Crude protein (\%) & 20.5 \\
Crede fat (\%) & 15.0 \\
Crude fiber (\%) & 3.0 \\
Crude ash (\%) & 11.0 \\
Calcium (\%) & 0.8 \\
Phosphorous (\%) & 1.5 \\
Vitamin A (U/kg) & 40,000 \\
\hline
\end{tabular}

throughout the experiment. Feces was obtained directly from the rectum of each piglet at 12 and $24 \mathrm{~h}$ and daily after d 1 post-challenge. Fecal consistency was scored according to a 4-ladder scale as described previously [26]: 0 , firm feces; 1 , soft feces; 2 , mild diarrhea; 3 , severe diarrhea. All animals were killed by electric stunning upon termination of the feeding trial, and the duodenum, jejunum, and ileum were dissected also as described [26].

\section{Detection of fecal shedding of PEDV}

RNA contained in the feces was extracted using RNasy Mini Kit ${ }^{\circ}$ (QIAGN, Germany) after removal of contaminants by centrifugation for $10 \mathrm{~min}$ at $4000 \times g$. Presence of PEDV in the sample was identified by the reverse transcription-polymerase chain reaction (RT-PCR) targeting a coding region of the membrane protein of the PEDV [14]. The base sequences of the forward and reverse primers were 5'-GGGCGCCTGTATAGAGTTTA-3' and 5'-AGACCACCAAGAATGTGTCC-3', respectively. The PCR conditions were initial denaturation at $95{ }^{\circ} \mathrm{C}$ for 2 min, 35 cycles of $95^{\circ} \mathrm{C}$ for $20 \mathrm{~s}, 56^{\circ} \mathrm{C}$ for $40 \mathrm{~s}$, and $72^{\circ}$ $\mathrm{C}$ for $1 \mathrm{~min}$, and final extension at $72{ }^{\circ} \mathrm{C}$ for $3 \mathrm{~min}$. A 412bp PCR product was identified by the agarose gel electrophoresis.

\section{Histopathological examination}

The intestinal tissue was fixed in a $10 \%$ neutral formalin solution. The fixed tissue was embedded in paraffin, sectioned to a 4- $\mu \mathrm{m}$ thickness, stained with hematoxylin and eosin, and subjected to measurement of the villus height $(\mathrm{VH})$ and crypt depth $(\mathrm{CD})$ under a microscopic field as previously described [26].

\section{Statistical analysis}

Data were analyzed using the GLM procedure of SAS (SAS Inst., USA) in all variables except for fecal PEDV shedding. The statistical model included the PEDV challenge and administration of the MYCI mixture as main effects as well as their interaction. In the frequency of fecal PEDV shedding, which was analyzed using the chisquared test of SAS, effects of the PEDV challenge and administration of the MYCI mixture were analyzed separately.

\section{Results}

\section{Growth performance}

The initial and final weights of the newborn piglets did not differ between the PEDV-challenged and unchallenged piglets or between the MYCI mixture-administered piglets and the vehicle (milk replacer)-administered (control) ones (Table 2). However, average daily gain (ADG) during the 7-d experimental period decreased $(p<0.01)$ due to the challenge ( 27 vs. $-6 \mathrm{~g}$ for the unchallenged vs. challenged group). The ADG increased $(p<0.05)$ in response 
Table 2 Effects of oral administration of the MYCl mixture on growth performance of newborn piglets after an oral administration of PEDV ${ }^{\mathrm{a}}$

\begin{tabular}{|c|c|c|c|c|c|c|c|c|c|}
\hline & \multicolumn{3}{|c|}{ Not challenged } & \multicolumn{3}{|c|}{ Challenged (Chal) } & \multicolumn{3}{|l|}{$P$-value } \\
\hline & $\mathrm{CON}^{\mathrm{b})}(n=5)$ & $\mathrm{MYCl}(n=5)$ & SEM & $\mathrm{CON}(n=6)$ & $\mathrm{MYCl}(n=6)$ & SEM & Chal & $\mathrm{MYCl}$ & $C \times M$ \\
\hline Initial wt, kg & 2.61 & 2.69 & 0.251 & 2.55 & 2.60 & 0.229 & 0.758 & 0.801 & 0.946 \\
\hline Final wt, kg & 2.80 & 2.89 & 0.258 & 2.43 & 2.65 & 0.235 & 0.232 & 0.545 & 0.797 \\
\hline$A D G^{b)}, g$ & 27 & 28 & 5.1 & -18 & 7 & 4.7 & $<0.001$ & 0.016 & 0.029 \\
\hline
\end{tabular}

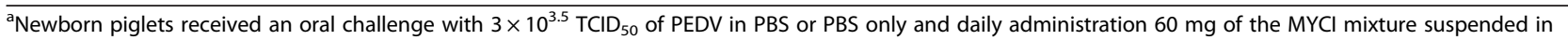
milk replacer or the vehicle for 7 days

${ }^{\mathrm{b}} \mathrm{CON}$, control; ADG, average daily gain

to administration of the MYCI mixture (17 g vs. $4 \mathrm{~g}$ for the MYCI vs. control group). Moreover, ADG increased due to administration of the MYCI mixture in the challenged piglets, but not in the unchallenged ones.

\section{Diarrhea and detection of fecal shedding of PEDV}

The piglets challenged with PEDV exhibited watery diarrhea beginning from d 2 post-challenge while unchallenged piglets had normal firm feces throughout the experiment (Figure 1). Administration of the MYCI mixture had no effect on the fecal consistency score. The presence of PED virus in the feces and in the small intestines was examined by RT-PCR (Table 3 and Fig. 2). When the virus was detected, it was present in both feces and small intestine (Fig. 2). The PEDV was detected in feces from $d 1$ through the end of the experiment only in the challenged piglets (Table 3). Moreover, the effect of the

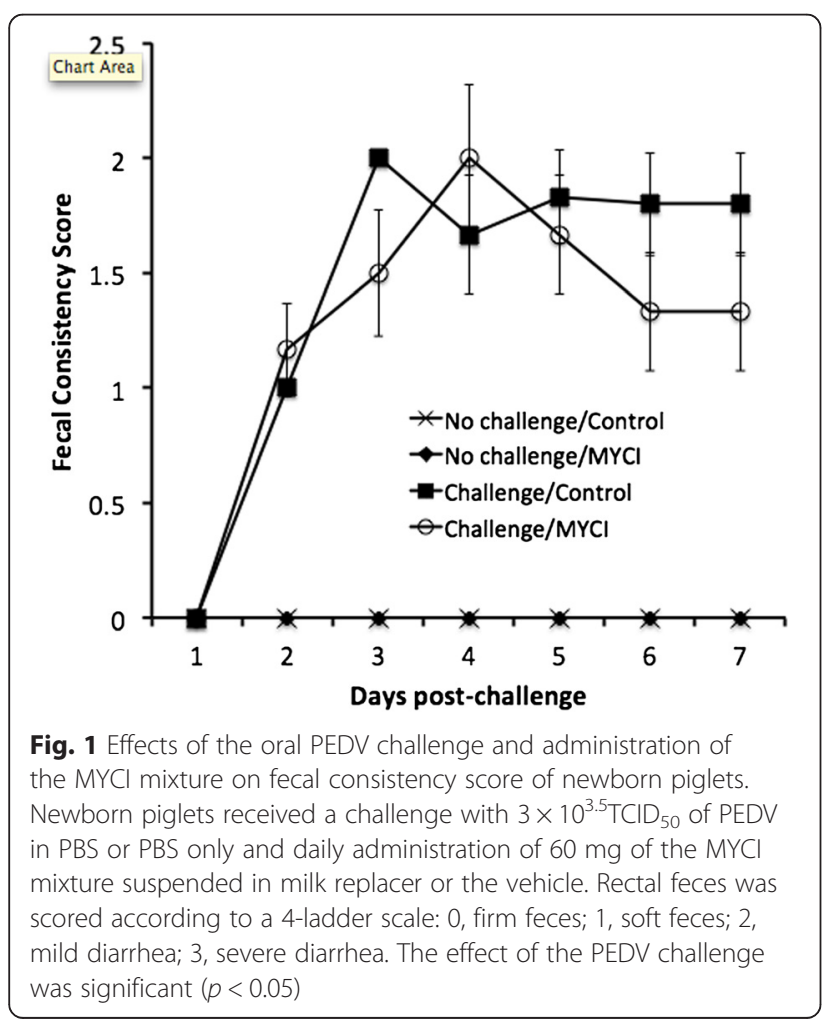

challenge on the frequency of the fecal PEDV shedding on d 1 onwards was significant $(p<0.05)$ whereas the effect of the MYCI administration was not significant at any time point of the experiment.

\section{Intestinal morphology}

The PEDV-challenged piglets exhibited a severe atrophy in the villus structure as well as hyperplasia with infiltration of inflammatory cells in the crypt in the duodenum, jejunum, and ileum when their intestinal morphology was compared with that of the unchallenged piglets (Fig. 3). The villus atrophy and crypt hyperplasia due to the PEDV infection were alleviated when the MYCI mixture was administered to the challenged piglets.

The VH in the duodenum decreased due to the PEDV challenge, but it increased in response to administration of the MYCI mixture (Table 4). Duodenal CD, however, was not influenced by the challenge or administration of the MYCI mixture. The VH:CD ratio in the duodenum was greater in the MYCI mixture-administered group vs. the control only in the animals challenged with PEDV. In the Jejunum, $\mathrm{VH}$, which did not change due to the challenge, increased in response to administration of the MYCI mixture. The CD in the jejunum increased due to the challenge. Moreover, $\mathrm{CD}$ in this region decreased in response to administration of the MYCI mixture, which was apparent only in the PEDV-challenged animals. The $\mathrm{VH}$ in the ileum also increased due to administration of the MYCI mixture, which was apparent only in the PEDV-challenged animals. The $\mathrm{CD}$ in the ileum decreased due to the PEDV challenge as well as administration of the MYCI mixture.

\section{Discussion}

While only sporadic PED outbreaks were reported in Europe during the past few decades, PEDV infection has caused enormous economic losses in the pig industry in Asian countries including China, South Korea and Vietnam during the same period. Furthermore, swine farmers in North America have also been experiencing devastating economic losses resulting from prevalence of PED since its outbreak in April of 2013 in the USA [27]. Because the efficacy of PEDV vaccines is not good enough 
Table 3 Effects of oral administration of the MYCI mixture on fecal PEDV shedding of newborn piglets after an oral administration of the virus ${ }^{\mathrm{a})}$

\begin{tabular}{|c|c|c|c|c|c|c|}
\hline \multirow[t]{2}{*}{ Time } & \multicolumn{2}{|l|}{ Not challenged } & \multicolumn{2}{|c|}{ Challenged (Chal) } & \multicolumn{2}{|l|}{$p$-value } \\
\hline & Control $(n=5)$ & $\mathrm{MYCl}(n=5)$ & Control $(n=6)$ & $\mathrm{MYCl}(n=6)$ & Chal & $\mathrm{MYCl}$ \\
\hline $\mathrm{Oh}$ & $0 / 5$ & $0 / 5$ & $0 / 6$ & $0 / 6$ & $N / A^{b}$ & $\overline{N / A}$ \\
\hline $12 \mathrm{~h}$ & $0 / 5$ & $0 / 5$ & $0 / 6$ & $0 / 6$ & N/A & N/A \\
\hline $1 d$ & $0 / 5$ & $0 / 5$ & $2 / 6$ & $2 / 6$ & 0.044 & 1.000 \\
\hline $2 d$ & $0 / 5$ & $0 / 5$ & $6 / 6$ & $6 / 6$ & $<0.001$ & 1.000 \\
\hline $3 d$ & $0 / 5$ & $0 / 5$ & $6 / 6$ & $5 / 6$ & $<0.001$ & 0.670 \\
\hline $4 d$ & $0 / 5$ & $0 / 5$ & $4 / 6$ & $2 / 6$ & 0.009 & 0.338 \\
\hline $5 d$ & $0 / 5$ & $0 / 5$ & $4 / 6$ & $3 / 6$ & 0.003 & 0.647 \\
\hline $6 d$ & $0 / 5$ & $0 / 5$ & $3 / 5^{c}$ & $3 / 6$ & 0.006 & 0.890 \\
\hline $7 d$ & $0 / 5$ & $0 / 5$ & $2 / 5$ & $2 / 6$ & 0.034 & 0.916 \\
\hline Total & $0 / 45$ & $0 / 45$ & $27 / 52$ & $23 / 54$ & $<0.001$ & 0.460 \\
\hline
\end{tabular}

${ }^{a}$ Newborn piglets received an oral challenge with $3 \times 10^{3.5} \mathrm{TCID}_{50}$ of PEDV in PBS or PBS only and daily administration 60 mg of the MYCI mixture suspended in milk replacer or the vehicle for 7 days. Presence of the PEDV in feces was determined by reverse transcription-polymerase chain reaction. Data represent the number of PEDV-positive animals per total animals

${ }^{\mathrm{b}} \mathrm{N} / \mathrm{A}$, Not applicable

${ }^{\mathrm{C}}$ One animal died

to prevent PEDV infection, it has been a research focus to search for safe, inexpensive and effective measures to prevent or treat PED. Accordingly, a variety of studies including the present one have been conducted in Europe, Asia, and America to find antiviral agents in medicinal herbs as a means of alternative medicine $[6,28]$.

Diarrhea and vomiting are the main clinical signs of PEDV infection resulting in suboptimal growth performance in suckling piglets [29]. The decreased ADG as well as diarrhea of the newborn piglets following the PEDV challenge in the present study was thus consistent with the known clinical signs of the virus infection [29, 30]. More importantly, administration of the MYCI mixture alleviated the growth check of the piglets due to the PEDV infection.

The PEDV infection causes gross and microscopic lesions such as severe atrophic enteritis with villous fusion similar to those found in the infection of the transmissible gastroenteritis virus [29, 31]. The atrophied villus structure as well as crypt hyperplasia indicated by the

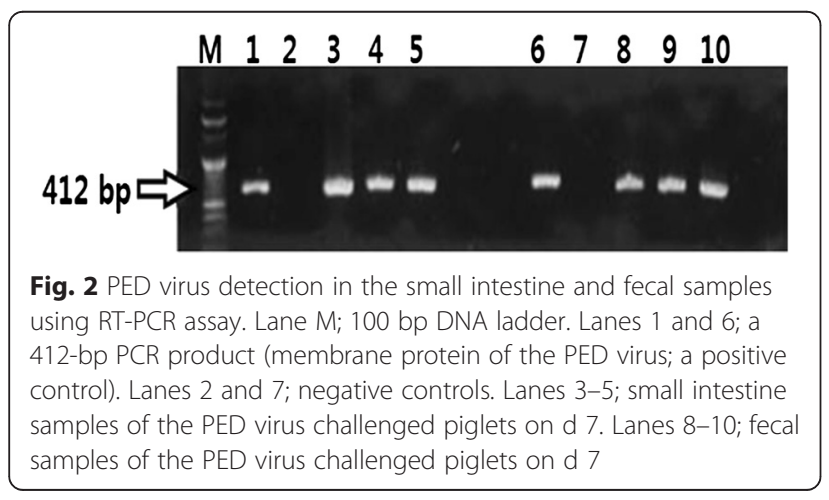

decreased $\mathrm{VH}$ and increased CD observed in the PEDVchallenged piglets was therefore consistent with the known histopathological signs of the PEDV infection. Furthermore, the increase in $\mathrm{VH}$ in the duodenum, jejunum, and ileum as well as the decrease in CD in the jejunum and ileum in response to administration of the MYCI mixture indicates that the MYCI recipe has a beneficial effect on the integrity of the intestinal mucosal structure of the piglets infected with PEDV.

The ultimate goal of PEDV vaccination is to prevent PEDV infection. However, currently available PEDV vaccines are not effective enough to prevent PED, although some of the vaccines are effective for alleviating fecal virus shedding and the severity of the clinical signs of PED [6]. In this regard, administration of the MYCI mixture was not effective for reducing the frequency of fecal PEDV shedding in the challenged piglets with all its positive effects on the integrity of the intestinal mucosal structure. Nevertheless, it is thought to be worth trying to examine if a combined use of a PEDV vaccine and the MYCI mixture has any synergistic prophylactic or therapeutic effect in PED.

A number of phytochemicals contained in medicinal plants, which include limonoids, alkaloids, lignana, organosulfur, furyl, thiophenes, polylines, terpenoids, flavonoids, polyphenolics, sulphides, saponins, coumarins, and chlorophyllins, are known to exhibit the antiviral effects by blocking viral entry or RNA/DNA replication or by virtue of their anti-oxidant activity [32]. Likewise, active antiviral phytochemicals, i.e. $11 \beta, 13$-dihydrotaraxinic acid, 6,7-dimethoxycoumarin, berberine, and indirubin, have been identified in Taraxaumi mongolicum [33], 6,7- Viola yedoensis Makino [34], Rhizoma coptidis [21], 


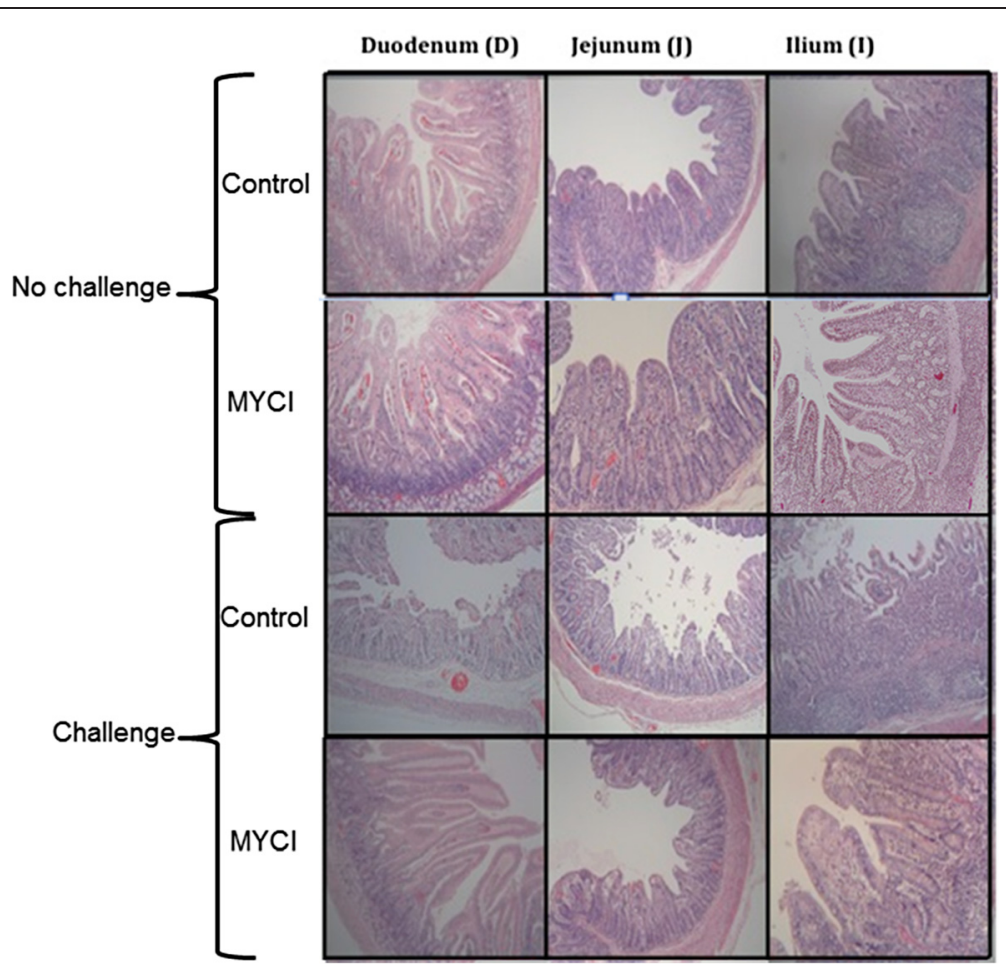

Fig. 3 Effects of the oral PEDV challenge and administration of the MYCI mixture on intestinal morphology of newborn piglets (100x magnification). Newborn piglets received a challenge with $3 \times 10^{3.5} \mathrm{TCID}_{50}$ of PEDV in PBS or PBS only and daily administration of $60 \mathrm{mg}$ of the $\mathrm{MYCl}$ mixture suspended in milk replacer or the vehicle for 7 days. Note the atrophied and fused villi as well as crypt hyperplasia in the challenged/control group and the alleviation of the atrophy and fusion of the villi and the crypt hyperplasia in the challenged/MYCI group compared with the morphology in the former. Only representative results are shown in this figure

Table 4 Effects of oral administration of the MYCI mixture on intestinal mucosal morphology of newborn piglets after an oral administration of PEDV ${ }^{\mathrm{a})}$

\begin{tabular}{|c|c|c|c|c|c|c|c|c|c|}
\hline & \multicolumn{3}{|c|}{ Not challenged } & \multicolumn{3}{|c|}{ Challenged (Chal) } & \multicolumn{3}{|c|}{$P$-value } \\
\hline & $\mathrm{CON}^{\mathrm{b})}(n=5)$ & $\mathrm{MYCl}(n=5)$ & SEM & $\operatorname{CON}(n=6)$ & $\mathrm{MYCl}(n=6)$ & SEM & Chal & $\mathrm{MYCl}$ & $C \times M$ \\
\hline \multicolumn{10}{|c|}{ Duodenum } \\
\hline$V H^{b)}, \mu m$ & 443 & 482 & 38.3 & 409 & 471 & 31.7 & 0.050 & $<0.001$ & 0.023 \\
\hline$C D^{b)}, \mu \mathrm{m}$ & 171 & 171 & 10.7 & 183 & 173 & 16.1 & 0.183 & 0.255 & 0.533 \\
\hline $\mathrm{VH}: \mathrm{CD}$ & 2.65 & 2.72 & 0.163 & 2.31 & 2.74 & 0.149 & 0.590 & 0.392 & 0.002 \\
\hline \multicolumn{10}{|l|}{ Jejunum } \\
\hline$V H, \mu m$ & 144 & 151 & 11.7 & 129 & 154 & 13.3 & 0.156 & 0.002 & 0.030 \\
\hline$C D, \mu \mathrm{m}$ & 157 & 137 & 13.0 & 170 & 138 & 9.5 & 0.040 & $<0.001$ & 0.001 \\
\hline $\mathrm{VH}: \mathrm{CD}$ & 0.98 & 1.18 & 0.166 & 0.89 & 1.23 & 0.155 & 0.946 & 0.377 & 0.013 \\
\hline \multicolumn{10}{|l|}{ Ilium } \\
\hline$V H, \mu m$ & 166 & 182 & 13.3 & 161 & 184 & 10.1 & 0.648 & $<0.001$ & 0.015 \\
\hline$C D, \mu \mathrm{m}$ & 165 & 166 & 15.9 & 160 & 142 & 11.0 & 0.001 & 0.027 & 0.048 \\
\hline $\mathrm{VH}: \mathrm{CD}$ & 1.12 & 1.16 & 0.156 & 1.01 & 1.32 & 0.170 & 0.933 & 0.547 & 0.058 \\
\hline
\end{tabular}

${ }^{\mathrm{a}}$ Newborn piglets received an oral challenge with $3 \times 10^{3.5} \mathrm{TCID}_{50}$ of PEDV in PBS or PBS only and daily administration $60 \mathrm{mg}$ of the MYCI mixture suspended in milk replacer or the vehicle for 7 days

${ }^{\mathrm{b}} \mathrm{CON}$, control; $\mathrm{VH}$, villus height; $\mathrm{CD}$, crypt depth 
and Radix isatidis [35], respectively, extracts of which were used in the present study. It also seems possible that there exist more active phytochemicals other than those described above in those herb extracts used in the present study, because the list of active components contained in medicinal herb extracts is rapidly expanding [36]. Overall, the present results suggest that administration of the MYCI mixture is a promising recipe which could be used as a prophylactic or therapeutic measure for PED.

\section{Conclusions}

We evaluated effects of a combined use of extracts of medicinal herbs Taraxaumi mongolicum, Viola yedoensis Makino, Rhizoma coptidis, and Radix isatidis (MYCI) on PED. In summary, medicinal herb extracts used in this study ameliorated impaired growth performance and intestinal lesion of newborn piglets challenged with the virulent PEDV. Therefore, our results suggest that the MYCI mixture could be used as a prophylactic or therapeutic agent in PED.

\section{Competing interests}

The authors declare that they have no competing interests.

\section{Authors' contributions}

SJK and $\mathrm{JHH}$ carried out the animal experiment. HBK, CYL, JHH and $\mathrm{KHC}$ analyzed data, and drafted the manuscript. All authors read and approved the final manuscript.

\section{Acknowledgments}

The present study was supported by 2014 Research Grant from Kangwon National University (No. 120141471) and the Regional Animal Industry Center at Gyeongnam National University of Science and Technology. The authors thank Jin Song (School of Medicine, Boston University) for critical reading of the manuscript.

\section{Author details}

${ }^{1}$ Department of Animal Resource and Science, Dankook University, Cheonan 330-714, South Korea. ${ }^{2}$ Regional Animal Industry Center, Gyeongnam National University of Science and Technology, Jinju 660-758, South Korea. ${ }^{3}$ Department of Veterinary Pathology, College of Veterinary Medicine and Institute of Veterinary Science, Kangwon National University, Chuncheon 200-701, South Korea. ${ }^{4}$ Department of Complementary and Alternative Medicine, College of Veterinary Medicine, University of Minnesota, Saint Paul 55108, USA.

Received: 26 May 2015 Accepted: 28 August 2015

Published online: 08 October 2015

\section{References}

1. Murphy FA, Gibbs EPJ, Horzinek MC, Studdert MJ. Veterinary Virology. 3rd ed. London: Academic press;1999. p. 23-42.

2. Weiss SR, Navas-Martin S. Coronavirus pathogenesis and the emerging pathogen severe acute respiratory syndrome coronavirus. Microbiol Mol Biol Rev. 2005;69(4):635-64.

3. Oh JS, Song DS, Yang JS, Song JY, Moon HJ, Kim TY, et al. Comparison of an enzyme-linked immunosorbent assay with serum neutralization test for serodiagnosis of porcine epidemic diarrhea virus infection. J Vet Sci. 2005;6(4):349-52.

4. Debouck P, Pensaert M. Experimental infection of pigs with a new porcine enteric coronavirus, CV 777. Am J Vet Res. 1980;41(2):219-23.

5. Park SJ, Song DS, Park BK. Molecular epidemiology and phylogenetic analysis of porcine epidemic diarrhea virus (PEDV) field isolates in Korea. Arch Virol. 2013;158(7):1533-41.
6. Song D, Park B. Porcine epidemic diarrhoea virus: a comprehensive review of molecular epidemiology, diagnosis, and vaccines. Virus Genes. 2012;44(2):167-75.

7. Kim O, Chae C. Application of reverse transcription polymerase chain reaction to detect porcine epidemic diarrhea virus in Vero cell culture. J Vet Diagn Invest. 1999;11(6):537-8.

8. Pansaert MB, DeBouck PA. A new coronavirus-like particle associated with diarrhea in swine. Arch Virol. 1978;58:243-7.

9. Briskin DP. Medicinal plants and phytomedicines. Linking plant biochemistry and physiology to human health. Plant Physiol. 2000;124(2):507-14.

10. Cowan MM. Plant products as antimicrobial agents. Clin Microbiol Rev. 1999;12(4):564-82.

11. Jassim SA, Naji MA. Novel antiviral agents: a medicinal plant perspective. J Appl Microbiol. 2003;95(3):412-27.

12. Wu CJ, Jan JT, Chen CM, Hsieh HP, Hwang DR, Liu HW, et al. Inhibition of severe acute respiratory syndrome coronavirus replication by niclosamide. Antimicrob Agents Chemother. 2004;48(7):2693-6.

13. Lu HM, Liang YZ, Yi LZ, Wu XJ. Anti-inflammatory effect of Houttuynia cordata injection. J Ethnopharmacol. 2006;104(1-2):245-9.

14. Kim O, Chae C. Comparison of reverse transcription polymerase chain reaction, immunohistochemistry, and in situ hybridization for the detection of porcine epidemic diarrhea virus in pigs. Can J Vet Res. 2002;66(2):112-6.

15. Kim HY, Shin HS, Park H, Kim YC, Yun YG, Park S, et al. In vitro inhibition of coronavirus replications by the traditionally used medicinal herbal extracts, Cimicifuga rhizoma, Meliae cortex, Coptidis rhizoma, and Phellodendron cortex. J Clin Virol. 2008;41(2):122-8.

16. Han H, He W, Wang W, Gao B. Inhibitory effect of aqueous Dandelion extract on HIV-1 replication and reverse transcriptase activity. BMC Complement Altern Med. 2011;11(112-6882):11-112.

17. Park KJ. Evaluation of in vitro antiviral activity in methanol extracts against influenza virus type A from Korean medicinal plants. Phytother Res. 2003;17:1059-63.

18. Shi S, Zhao $Y$, Zhou H, Zhang $Y$, Jiang $X$, Huang K. Identification of antioxidants from Taraxacum mongolicum by high-performance liquid chromatography-diode array detection-radical-scavenging detection-electrospray ionization mass spectrometry and nuclear magnetic resonance experiments. J Chromatogr A. 2008;1209(1-2):145-52.

19. Li C, Chu IC, Liao HF. Investigating the immunomodulatory effects of Chinese herbs on mouse. J Immunol. 2009;182:43.16.

20. Xie C, Kokubun T, Houghton PJ, Simmonds MS. Antibacterial activity of the Chinese traditional medicine, Zi Hua Di Ding. Phytother Res. 2004;18(6):497-500.

21. Chin LW, Cheng YW, Lin SS, Lai YY, Lin LY, Chou MY, et al. Anti-herpes simplex virus effects of berberine from Coptidis rhizoma, a major component of a Chinese herbal medicine, Ching-Wei-San. Arch Virol. 2010;155(12):1933-41.

22. Kong WJ, Zhao YL, Xiao XH, Wang JB, Li HB, Li ZL, et al. Spectrum-effect relationships between ultra performance liquid chromatography fingerprints and anti-bacterial activities of Rhizoma coptidis. Anal Chim Acta. 2009;634(2):279-85.

23. Shin EK, Kim DH, Lim H, Shin HK, Kim JK. The anti-inflammatory effects of a methanolic extract from Radix Isatidis in murine macrophages and mice. Inflammation. 2010;33(2):110-8.

24. Chen X, Wang Z, Yang Z, Wang J, Xu Y, Tan RX, et al. Houttuynia cordata blocks HSV infection through inhibition of NF-kappaB activation. Antiviral Res. 2011:92(2):341-5.

25. Zhao YL, Wang JB, Shan LM, Jin C, Ma L, Xiao XH. Effect of Radix isatidis polysaccharides on immunological function and expression of immune related cytokines in mice. Chin J Integr Med. 2008;14(3):207-11.

26. Kwon CH, Lee CY, Han SJ, Kim SJ, Park BC, Jang I, et al. Effects of dietary supplementation of lipid-encapsulated zinc oxide on colibacillosis, growth and intestinal morphology in weaned piglets challenged with enterotoxigenic Escherichia coli. Anim Sci J. 2014;85(8):805-13.

27. Vlasova AN, Marthaler D, Wang Q, Culhane MR, Rossow KD, Rovira A, et al. Distinct characteristics and complex evolution of PEDV strains, North America, May 2013-February 2014. Emerg Infect Dis. 2014;20(10):1620-8.

28. Lee JH, Park JS, Lee SW, Hwang SY, Young BE, Choi HJ. Porcine epidemic diarrhea virus infection: Inhibition by polysaccharide from Ginkgo biloba exocarp and mode of its action. Virus Res. 2014;195C:148-52. 
29. Madson DM, Magstadt DR, Arruda PH, Hoang H, Sun D, Bower LP, et al. Pathogenesis of porcine epidemic diarrhea virus isolate (US/lowa/18984/ 2013) in 3-week-old weaned pigs. Vet Microbiol. 2014;174(1-2):60-8.

30. Kim O, Chae C. Experimental infection of piglets with a korean strain of porcine epidemic diarrhoea virus. J Comp Pathol. 2003;129(1):55-60.

31. Coussement W, Ducatelle R, Debouck P, Hoorens J. Pathology of experimental CV777 coronavirus enteritis in piglets. I. Histological and histochemical study. Vet Pathol. 1982;19(1):46-56.

32. Naithani R, Huma LC, Holland LE, Shukla D, McCormick DL, Mehta RG, et al. Antiviral activity of phytochemicals: a comprehensive review. Mini Rev Med Chem. 2008;8(11):1106-33.

33. Liu J, Zheng N, Liu M. A new inositol triester from Taraxacum mongolicum. Natural Product Research, Nat Prod Res. 2014;28(7):420-3.

34. Sun Y, Du L, Zhou L, Zhang W, Miao F, Yang X, et al. Study on antibacterial active components from Viola yedoensis. Zhongguo Zhongyao Zazhi. 2011;36(19):2666-71.

35. YE W, LI X, CHENG J. screening of eleven chemical constituents from Radix isatidis for antiviral activity. Afr J Pharm and Pharmaco. 2011;5(16):1933-6.

36. Shi SY, Zhou CX, Xu Y, Tao QF, Bai H, Lu FS, et al. Studies on chemical constituents from herbs of Taraxacum mongolicum. Zhongguo Zhong Yao Za Zhi. 2008;33(10):1147-57.

\section{Submit your next manuscript to BioMed Central and take full advantage of:}

- Convenient online submission

- Thorough peer review

- No space constraints or color figure charges

- Immediate publication on acceptance

- Inclusion in PubMed, CAS, Scopus and Google Scholar

- Research which is freely available for redistribution 